\title{
A Retrospective Study of Disparities in an Academic Ophthalmic Emergency Department
}

\author{
Colleen Szypko, BA ${ }^{1,2}$ Nathan Hall, MS ${ }^{1}$ Thong Ta, BS ${ }^{1}$ Matthew F. Gardiner, MD ${ }^{1}$ \\ Alice C. Lorch, MD, MPH${ }^{1}$
}

${ }^{1}$ Department of Ophthalmology, Harvard Medical School, Boston, Massachusetts

2 New York Institute of Technology College of Osteopathic Medicine,

Address for correspondence Alice Lorch, MD, MPH, 243 Charles

Street, Boston, MA 02114 (e-mail: Alice_Lorch@meei.harvard.edu).

Old Westbury, New York

J Acad Ophthalmol 2021;13:e277-e287.

\begin{abstract}
Keywords

- social determinants of health

- ophthalmic emergency room

- disparities

- equity

Purpose Emergency medicine is a common access point to health care; disparities in this care by demographic characteristics, including race and ethnicity, may affect outcomes. The Massachusetts Eye and Ear (MEE) Emergency Department (ED) is a subspecialty emergency department; data from this site can be utilized to better understand social determinants of quality ophthalmic care.

Design This is a retrospective cross sectional cohort study in the MEE ED examining patient visits from June 1, 2016 to June 30, 2019.

Methods Using the electronic medical record system, all unique visits were identified between June 1, 2016 and June 30, 2019 (inclusive); patient demographics (sex, race, ethnicity [Hispanic vs. non-Hispanic], primary care provider [PCP] status, insurance type, zip code, primary language), date of visit, triage category and outcomes (final diagnosis, visit duration, and next visit at MEE within 3 months of the ED visit) were collected. Kaplan-Meier plots were used to visualize likelihood of follow-up visit to MEE for urgent patients based on demographics. Multivariate linear regression was used to examine factors affecting visit durations, as stratified by urgency, and Cox proportional hazards regression was used to establish hazard ratios for next visit to MEE.

Results Of the 46,248 ophthalmology ED initial visits, only triage status, season of visit, out-of-state residency, Medicare coverage, and Medicaid coverage led to statistically significant differences in visit durations for urgent visits compared with the respective reference groups. Similar trends persisted within the non-urgent visit cohort for visit durations. Residency, insurance coverage, season of visit, race, PCP status, and sex were identified as statistically significant predictors of the likelihood of a follow-up visit.

Conclusion Data from an ophthalmic emergency department suggest that demographic factors do impact patient visit duration and time to follow-up visit. These findings suggest a continued need for attention to social determinants of health and equitable care of patients within ophthalmology.
\end{abstract}

received

May 5, 2021

accepted after revision

August 5, 2021
DOI https://doi.org/

10.1055/s-0041-1736439.

ISSN 2475-4757.

\footnotetext{
(C) 2021. The Author(s).

This is an open access article published by Thieme under the terms of the Creative Commons Attribution-NonDerivative-NonCommercial-License, permitting copying and reproduction so long as the original work is given appropriate credit. Contents may not be used for commercial purposes, or adapted, remixed, transformed or built upon. (https://creativecommons.org/ licenses/by-nc-nd/4.0/)

Thieme Medical Publishers, Inc., 333 Seventh Avenue, 18th Floor, New York, NY 10001, USA
} 
Emergency rooms are increasingly used as an access point for health care, often when patients do not have adequate access to primary care. ${ }^{1-5}$ Studies suggest that the proportion of adult Americans with an identified source of primary care has decreased slightly in recent years, declining from $77 \%$ in 2002 to $75 \%$ in 2015 . $^{3}$ Depending on the method of categorization, emergency room visits can be determined as "nonurgent" 4.8 to $90 \%$ of the time, with a median of $32 \%{ }^{6}$ This may suggest a lack of understanding of the severity of symptoms in addition to a lack of access to outpatient care. Frequent, repeated, ED visits are common in patients with complex medical and psychosocial histories but are also seen among patients without these histories. ${ }^{7,8}$

One consequence of frequent ED use can be long wait times and visit durations; in the United States the average ED visit length is 4.12 hours. ${ }^{9,10}$ In a study of hospitals nationwide conducted in 2006, the majority of hospitals failed to comply with ED wait times recommended on a four-level triage scale (emergent, urgent, semi-urgent, non-urgent) by the National Quality Forum, a national not-for-profit, nonpartisan organization. ${ }^{11}$ Literature regarding the potential for demographic factors to influence triage decisions and health care in the ED setting is varied. Despite some research refuting the role of bias in clinician decision-making at triage, other studies do suggest that demographic factors can lead to disparities in care in the ED setting. ${ }^{12-20}$

The Massachusetts Eye and Ear (MEE) Emergency Department (ED) is a subspecialty emergency department open for ophthalmic care 24 hours a day 7 days a week, and is one of four ophthalmology-specific emergency departments in the United States. Patients present from throughout New England and are treated regardless of insurance status. Internal quality metrics, published in an annual MEE Quality \& Outcomes report, show that there were 15,997 initial and 1,797 follow-up visits to the MEE ED in 2019; the top 20 urgent diagnoses represented 4,193 , or $26.2 \%$ of initial visits as determined by expert opinion (-Table 1). ${ }^{21}$ In 2019 the average visit duration in the MEE ED was 2.9 hours, which is well below the national average. Patients in the MEE ED are offered follow-up visits if needed for subsequent clinical care; this is usually in the ambulatory setting but can take place in the ED if ambulatory appointments are not available. In this paper, we examine the demographics of patients in this specialty emergency department, and the effect of particular demographic factors on visit duration and follow-up visits.

\section{Methods}

Ophthalmology emergency department initial visits at Mass Eye and Ear from June 1, 2016 to June 30, 2019 were extracted from the electronic medical record (EMR). Fields that were extracted for each ED visit included: sex, race, ethnicity (Hispanic vs. non-Hispanic), primary care provider (PCP) status, insurance type, zip code, primary language, triage category, final diagnosis, and visit duration. The date of the next ophthalmology visit (surgical visit, clinical visit, or repeat ED visit) to MEE, following the original ED visit, was also extracted. The Massachusetts Eye and Ear Institutional
Table 1 Urgent ophthalmic diagnosis

\begin{tabular}{|l|l|}
\hline Abscess of eyelid & Keratoconus \\
\hline Anisocoria & Laceration of eyelid \\
\hline Burn & Macular hole \\
\hline Canaliculitis & Optic neuritis \\
\hline Central serous retinopathy & Other ocular foreign body \\
\hline Contusion of eye & Orbital fracture \\
\hline Corneal foreign body & Orbital inflammation \\
\hline Corneal ulcer & Papilledema \\
\hline Dacryoadenitis & Retina artery occlusion \\
\hline Dacryocystitis & Retinal break \\
\hline Diplopia & Retinal detachment \\
\hline Dislocation of lens & Retinal hemorrhage \\
\hline Endophthalmitis & Retinal vascular occlusion \\
\hline Glaucoma & Retinal vein occlusion \\
\hline Globe trauma & Scleritis \\
\hline Hypopyon & Uveitis \\
\hline Iridocyclitis & Visual field defect \\
\hline Iridodialysis & Vitreous hemorrhage \\
\hline Keratitis & \\
\hline
\end{tabular}

Review Board deemed this research exempt. Our study adheres to the tenets of the Declaration of Helsinki. Obtaining informed consent was not required due to the retrospective nature of our study.

Race was self-reported by patients upon first registration to MEE. The distinct options available in the EMR for race during the study period were White, American Indian or Alaska Native, Asian, Black or African American, Native Hawaiian or Other Pacific Islander, and Hispanic. There was an additional field that designated patients as Hispanic or Not Hispanic ethnicity, which was also self-reported. If a patient was unable to provide this information or declined to report, it was marked as "unknown." In addition, any blank field for race or Hispanic versus non-Hispanic ethnicity was marked as "unknown" in the dataset.

Insurance type was categorized into seven categories: private, accidental, CHIP, government, Medicaid, Medicare, other, and no insurance. All 259 unique insurances were identified and categorized into these eight categories. Insurances that contained key phrases of "Medicare," "MassHealth," or "Medicaid" were categorized into "Medicare," "government," and "Medicaid," respectively. Any medical plan containing the phrase "Children Medical Security" was categorized as CHIP. Insurance sponsored by municipalities, state, federal, and military organizations were considered to be government issued plans. Any policies that were under the jurisdiction of worker's compensation or through auto-policies were recognized as accidental insurances. Private insurance was then identified and reviewed to avoid conflicts with the other classifications. Insurance policies that did not belong to any of the aforementioned categories 
were categorized as "other." This included international policies, student insurances, and other generic medical insurances. Fields that had no insurance were considered to be uninsured. This method was based on other studies using a similar method for categorization of insurance types. $^{10,15,20}$

Zip codes were bucketed into the respective Massachusetts counties using open source data. Any patients that did not have an in-state zip code were categorized as "out of state."

Visit duration was defined as the difference between the time of initial check-in at MEE ED and the discharge time, which were both marked in the EMR.

Triage category was determined by a nurse at presentation using a pre-determined list of chief complaints. Triage Category 1 was described as "Emergency," Category 2 as "Urgent" and Category 3 as "non-urgent." This triage was used to expedite certain patients to the attention of a physician.

The final billing diagnosis was categorized as urgent or non-urgent using a method established for the annual MEE Quality and Outcomes report. ${ }^{21}$ This differentiation was based on clinical expertise of a reviewing clinician team; potential urgent diagnoses included abscess of eyelid, anisocoria, burn, canaliculitis, central serious retinopathy, contusion of eye, corneal foreign body, corneal ulcer, dacryoadenitis, dacryocystitis, diplopia, dislocation of lens, endophthalmitis, glaucoma, globe trauma, hypopyon, iridocyclitis, iridodialysis, keratitis, keratoconus, laceration of eyelid, macular hole, optic neuritis, other ocular foreign body, orbital fracture, orbital inflammation, papilledema, retinal artery occlusion, retinal break, retinal detachment, retinal hemorrhage, retinal vascular occlusion, retinal vein occlusion, scleritis, uveitis, visual field defect, and vitreous hemorrhage. Diagnoses that did not fall in the above categories were considered non-urgent.

Subsequent visit was defined as any ophthalmology visit to MEE, starting from the day after presentation up to 3 months after the anchor ED visit. Same day visits were not included, as they were considered to be part of the episodes of emergency medical care. These subsequent visits included subspecialty ophthalmology clinic visits, another ED visit, a surgery, or an inpatient visit. After 3 months, a repeat ED visit by a patient was considered a new initial ED visit.

Descriptive statistics were calculated for all baseline covariates and demographic variables of interest. Multivariate linear regression models were fit to examine factors affecting ED visit durations, as stratified by urgency. Both a fully saturated model and a final model were fit for each urgency status. Final models were determined using automated stepwise selection utilizing Akaike's Information Criterion (AIC). ${ }^{22}$ Kaplan Meier (KM) curves were fit to the data to model the probability of survival as defined as time to follow-up visit at MEE for urgent patients based on the state of residency, biological sex, and primary language. Log-rank tests were conducted to compare survival curves on each KM plot. Cox proportional hazards (PHs) models were fit to model the hazard of having another visit with MEE within 3 months after an anchor ED visit, stratified by urgency of the visit. Robust standard errors were used in all Cox PH models to relax the assumption of $\mathrm{PH}$ across all covariates of interest. $^{23,24}$ All analyses were conducted using R, version 4.0.0.

\section{Results}

There were a total of 46,248 initial ophthalmology ED visits at Mass Eye and Ear from June 12016 to June 31 2019. - Table 2 contains case level demographic data for these visits. No table findings from this table include: $29.7 \%$ of visits involved a patient with no listed PCP, $20.16 \%$ of visits were by non-White patients, $9.49 \%$ of visits were with patients who did not report English as their primary language, $13.21 \%$ of visits were by patients who lived outside of Massachusetts, and $27.64 \%$ of visits were associated with an urgent final primary diagnosis.

-Table 3 presents the full model for visit durations and -Table 4 presents the final statistical model which includes variables for which a statistically significant difference was observed. Mean visit durations across demographic variables and subsequent $\beta$ coefficients and $p$-values stratified by urgency are shown.

The average visit duration for in-state patients was shorter than the average visit duration for out-of-state patients, holding all other variables constant. This was true for both urgent and non-urgent visits $(\beta-138.73, p<0.0001$; $\beta-47.26, p<0.0001)$. Insurance status also impacted visit length. Patients with Medicaid had significantly longer visits for both urgent and non-urgent diagnoses ( $\beta$ 73.57, $p=0.0022 ; \beta$ 28.16, $p=0.0003$.). Patients with Medicare also had significantly longer visits for both urgent and non-urgent diagnoses $(\beta$ 105.29, $p<0.0001 ; \beta 38.10, p$ $<0.0001$.). In addition, patients without insurance had longer visits, but only for non-urgent diagnoses ( $\beta$ 31.51, $p=0.0025$.). Both urgent and non-urgent visits were significantly shorter in Winter, Spring, and Summer compared with Fall. Both urgent and non-urgent visits were significantly shorter for triage categories two and three compared with triage category one.

No significant differences in visit durations were demonstrated based on race, ethnicity (Hispanic vs. non-Hispanic), sex, PCP status, or primary language categories among urgent or non-urgent visits (-Table $\mathbf{3}$ ).

- Table 5 presents hazard ratios across demographic variables for the probability of having another visit with MEE within 3 months after an anchor ED visit, stratified by urgency of the visit. For urgent visits, out-of-state residency, Black race, and four types of insurance (accidental, CHIP, Medicaid, and Medicare) significantly decreased the chance of having a follow-up appointment compared with in-state residency, White race, and private insurance, respectively. For non-urgent visits, out-of-state residency, three insurance types (Accidental, CHIP, Medicare), season of visit (Winter and Spring), association with a PCP and female sex significantly decreased the chance of having a follow-up appointment when compared with in-state residency, private 
Table 2 Case level demographics of MEE Ophthalmology ED visits from June 1, 2016 to June 31, 2019, $n=46,248$

\begin{tabular}{|c|c|}
\hline Demographic & Count (\%) \\
\hline \multicolumn{2}{|l|}{ Biological sex } \\
\hline Male & 24,507 (52.99) \\
\hline Female & $21,739(47.01)$ \\
\hline Unknown & $2(0.00)$ \\
\hline \multicolumn{2}{|l|}{ Race $^{a}$} \\
\hline American Indian & $85(0.21)$ \\
\hline Asian & $2,958(7.19)$ \\
\hline Black & $2,644(11.32)$ \\
\hline Hawaiian & $129(0.31)$ \\
\hline Hispanic & $461(1.12)$ \\
\hline White & $32,832(79.84)$ \\
\hline Unknown & $5,128(11.10)$ \\
\hline \multicolumn{2}{|c|}{ Ethnicity (Hispanic vs. Non-Hispanic) ${ }^{a}$} \\
\hline Hispanic & $4,515(9.83)$ \\
\hline Non-Hispanic & $41,398(90.17)$ \\
\hline Unknown & $335(0.72)$ \\
\hline \multicolumn{2}{|l|}{ Primary Language } \\
\hline English & $41,147(90.51)$ \\
\hline Non English & $4,316(9.49)$ \\
\hline Unknown & $785(1.70)$ \\
\hline \multicolumn{2}{|c|}{ In state vs. Out of state } \\
\hline In state & $40,141(86.80)$ \\
\hline Out of state & $6,107(13.21)$ \\
\hline \multicolumn{2}{|l|}{ Listed PCP } \\
\hline Yes & $32,503(70.28)$ \\
\hline No & $13,745(29.72)$ \\
\hline Unknown & $1,334(2.88)$ \\
\hline \multicolumn{2}{|l|}{ Primary Insurance } \\
\hline Accidental & $919(2.13)$ \\
\hline CHIP & $44(0.10)$ \\
\hline Government & $1,174(2.72)$ \\
\hline Medicaid & $6,131(14.19)$ \\
\hline Medicare & $10,020(23.20)$ \\
\hline Private & $24,617(57.00)$ \\
\hline Other & $285(0.66)$ \\
\hline No insurance & $3,058(6.61)$ \\
\hline \multicolumn{2}{|l|}{ Final diagnosis } \\
\hline Urgent & $12,782(27.64)$ \\
\hline Non-urgent & $33,466(72.36)$ \\
\hline \multicolumn{2}{|l|}{ Triage category } \\
\hline 1 (Emergency) & $1,094(2.37)$ \\
\hline 2 (Urgent) & $33,720(72.92)$ \\
\hline
\end{tabular}

insurance, fall season, no association with a provider and male sex, respectively. Primary language (English vs. nonEnglish) did not affect the chance of having a follow-up appointment either for urgent or non-urgent visits. Ethnicity (Hispanic vs. non-Hispanic) similarly did not affect the chance of having a follow-up appointment either for urgent or non-urgent visits.

The Kaplan-Meier (KM) plots (-Fig. 1) present survival analysis for variables with statistically significant $p$-values from the log-rank test comparing survival probability of having a follow-up after initial ED visit over time. For nonurgent visits, there is a statistically significant difference between the survival pattern of having another visit at MEE in the 3 months following their ED visit comparing males to females (-Fig. 1a). For urgent visits, there is a statistically significant difference between this survival pattern comparing in state residents to out of state residents (-Fig. 1b), comparing patients where English is their primary language to non-English speaking patients (-Fig. 1c), non-Hispanic

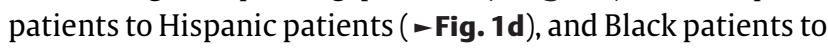
White patients (-Fig. 1e). The $p$-value depicted on the KM plots is derived from the log-rank test, which is a nonparametric test that has been conducted on a single variable of interest, whereas the $p$-values from the Cox $\mathrm{PH}$ regression models are derived from a semi-parametric test of the survival function of multiple covariates at once. That is, any particular covariate's univariate statistical significance from preliminary KM plot results may change or shift, depending on its effect on survival after adjusting for all other covariates of interest in the Cox PH regression model, especially if the assumption of $\mathrm{PH}$ is violated for the covariate in question.

\section{Discussion}

Demographic data from patients seeking urgent care at an ophthalmic emergency room can potentially serve as a window into social determinants of care throughout the field. This study examines many of those factors and their effect on the visits durations and likelihood to follow-up within the same hospital system. In doing so we identify potential disparities in care that can be further investigated and addressed to improve equity of care and outcomes.

Overall, this study demonstrates that, in our population, race, ethnicity (Hispanic vs. non-Hispanic), sex, and primary language did not affect the length of a patient's ED visit for an 
Table 3 Full MEE Ophthalmology ED visit durations multiple linear regression model, with all variables regardless of statistical significance (supplemental section)

\begin{tabular}{|c|c|c|c|c|c|c|}
\hline \multirow[b]{2}{*}{ Demographic $^{a}$} & \multicolumn{3}{|l|}{ Urgent visits } & \multicolumn{3}{|l|}{ Non-urgent visits } \\
\hline & $\begin{array}{l}\text { Mean visit } \\
\text { duration } \\
\text { min, (SD) }\end{array}$ & $\beta[95 \% \mathrm{Cl}]$ & $p$ & $\begin{array}{l}\text { Mean visit } \\
\text { duration } \\
\text { min, (SD) }\end{array}$ & $\beta[95 \% \mathrm{Cl}]$ & $p$ \\
\hline \multicolumn{7}{|l|}{ Residency } \\
\hline Out of state & $471.78(1,156.03)$ & - & - & $230.25(693.40)$ & - & - \\
\hline In state & $\begin{array}{l}298.81 \\
(704.88)\end{array}$ & $\begin{array}{l}-137.44 \\
{[-176.52,} \\
-98.36]\end{array}$ & $<0.0001$ & $182.76(346.12)$ & $\begin{array}{l}-47.97 \\
{[-62.54} \\
-33.41]\end{array}$ & $<0.0001$ \\
\hline \multicolumn{7}{|c|}{ Primary insurance } \\
\hline Private & $\begin{array}{l}277.13 \\
(668.30)\end{array}$ & - & - & $173.20(264.59)$ & - & - \\
\hline Accidental & $\begin{array}{l}428.54 \\
(853.67)\end{array}$ & $\begin{array}{l}68.69 \\
{[-18.01,155.39]}\end{array}$ & 0.1204 & $179.12(260.65)$ & $\begin{array}{l}-10.37 \\
{[-50.10,29.36]}\end{array}$ & 0.6091 \\
\hline $\mathrm{CHIP}$ & $\begin{array}{l}249.62 \\
(99.66)\end{array}$ & $\begin{array}{l}-129.46 \\
{[-1,005.66,746.75]}\end{array}$ & 0.7721 & $\begin{array}{l}193.67 \\
(70.37)\end{array}$ & $\begin{array}{l}17.41 \\
{[-202.82,237.64]}\end{array}$ & 0.8769 \\
\hline Government & $383.68(1,122.60)$ & $\begin{array}{l}62.20 \\
{[-28.99,153.39]}\end{array}$ & 0.1813 & $183.26(270.88)$ & $\begin{array}{l}8.326 \\
{[-22.82,39.47]}\end{array}$ & 0.6002 \\
\hline Medicaid & $\begin{array}{l}357.93 \\
(831.96)\end{array}$ & $\begin{array}{l}71.28 \\
{[22.64,119.92]}\end{array}$ & 0.0041 & $198.30(465.42)$ & $\begin{array}{l}27.08 \\
{[11.06,43.10]}\end{array}$ & 0.0009 \\
\hline Medicare & $433.62(1,070.02)$ & $\begin{array}{l}92.46 \\
{[46.83,138.09]}\end{array}$ & 0.0001 & $217.16(526.33)$ & $\begin{array}{l}37.29 \\
{[22.97,51.61]}\end{array}$ & $<0.0001$ \\
\hline Other & $\begin{array}{l}213.73 \\
(128.00)\end{array}$ & $\begin{array}{l}-25.11 \\
{[-244.98,194.77]}\end{array}$ & 0.8229 & $177.01(132.44)$ & $\begin{array}{l}-5.67 \\
{[-72.31,60.97]}\end{array}$ & 0.8675 \\
\hline No insurance & $\begin{array}{l}321.06 \\
(614.66)\end{array}$ & $\begin{array}{l}-8.33 \\
{[-69.04,52.37]}\end{array}$ & 0.7878 & $210.65(773.00)$ & $\begin{array}{l}31.47 \\
{[10.67,52.26]}\end{array}$ & 0.003 \\
\hline \multicolumn{7}{|l|}{ Season of visit } \\
\hline Fall & $385.17(1,025.61)$ & - & - & $209.73(500.58)$ & - & - \\
\hline Spring & $\begin{array}{l}302.24 \\
(667.92)\end{array}$ & $\begin{array}{l}-77.59 \\
{[-118.38,} \\
-36.80]\end{array}$ & 0.0002 & $174.93(348.56)$ & $\begin{array}{l}-34.72 \\
{[-47.97} \\
-21.48]\end{array}$ & $<0.0001$ \\
\hline Summer & $\begin{array}{l}322.58 \\
(699.87)\end{array}$ & $\begin{array}{l}-55.61 \\
{[-95.73} \\
-15.50]\end{array}$ & 0.0066 & $189.05(383.32)$ & $\begin{array}{l}-21.48 \\
{[-34.50} \\
-8.45]\end{array}$ & 0.0012 \\
\hline Winter & $\begin{array}{l}308.23 \\
(800.37)\end{array}$ & $\begin{array}{l}-58.34 \\
{[-100.78} \\
-15.90]\end{array}$ & 0.0071 & 181.53 (381.93) & $\begin{array}{l}-27.45 \\
{[-41.42} \\
-13.47]\end{array}$ & 0.0001 \\
\hline \multicolumn{7}{|l|}{ Race $^{a}$} \\
\hline White & $338.06(830.44)$ & - & - & $189.01(405.82)$ & - & - \\
\hline $\begin{array}{l}\text { American } \\
\text { Indian }\end{array}$ & $761.50(2,336.11)$ & $\begin{array}{l}473.75 \\
{[94.19,853.30]}\end{array}$ & 0.0144 & $155.61(110.29)$ & $\begin{array}{l}-22.02 \\
{[-123.70,79.66]}\end{array}$ & 0.6712 \\
\hline Asian & $249.11(409.12)$ & $\begin{array}{l}-41.24 \\
{[-103.80,21.33]}\end{array}$ & 0.1964 & $175.34(356.11)$ & $\begin{array}{l}-4.17 \\
{[-22.79,14.44]}\end{array}$ & 0.6603 \\
\hline Black & $312.43(785.46)$ & $\begin{array}{l}1.31 \\
{[-46.46,49.09]}\end{array}$ & 0.957 & $196.63(455.10)$ & $\begin{array}{l}9.25 \\
{[-6.06,24.56]}\end{array}$ & 0.2365 \\
\hline Hawaiian & $251.51(234.91)$ & $\begin{array}{l}-75.80 \\
{[-351.79,200.18]}\end{array}$ & 0.5903 & $164.96(82.27)$ & $\begin{array}{l}-27.57 \\
{[-110.35,55.21]}\end{array}$ & 0.5139 \\
\hline Hispanic & $260.60(381.22)$ & $\begin{array}{l}-83.97 \\
{[-242.89,74.94]}\end{array}$ & 0.3003 & $187.38(309.03)$ & $\begin{array}{l}-6.86 \\
{[-55.39,41.66]}\end{array}$ & 0.7816 \\
\hline \multicolumn{7}{|c|}{ Ethnicity(Hispanic vs. non-Hispanic) ${ }^{a}$} \\
\hline Non-Hispanic & $329.31(808.27)$ & - & - & $188.49(408.82)$ & - & - \\
\hline
\end{tabular}


e282 A Retrospective Study of Disparities Szypko et al.

Table 3 (Continued)

\begin{tabular}{|c|c|c|c|c|c|c|}
\hline \multirow[b]{2}{*}{ Demographic $^{a}$} & \multicolumn{3}{|l|}{ Urgent visits } & \multicolumn{3}{|l|}{ Non-urgent visits } \\
\hline & $\begin{array}{l}\text { Mean visit } \\
\text { duration } \\
\text { min, (SD) }\end{array}$ & $\beta[95 \% \mathrm{Cl}]$ & $p$ & $\begin{array}{l}\text { Mean visit } \\
\text { duration } \\
\text { min, (SD) }\end{array}$ & $\beta[95 \% \mathrm{Cl}]$ & $p$ \\
\hline Hispanic & $\begin{array}{l}331.12 \\
(754.56)\end{array}$ & $\begin{array}{l}19.54 \\
{[-59.37,98.45]}\end{array}$ & 0.6274 & $192.49(347.10)$ & $\begin{array}{l}11.51 \\
{[-14.25,37.27]}\end{array}$ & 0.3811 \\
\hline \multicolumn{7}{|l|}{ Listed PCP } \\
\hline No & $348.09(767.01)$ & - & - & $192.03(458.25)$ & - & - \\
\hline Yes & $321.05(822.61)$ & $\begin{array}{l}0.60 \\
{[-32.55,33.75]}\end{array}$ & 0.9717 & $187.61(388.33)$ & $\begin{array}{l}1.50 \\
{[-10.25,13.25]}\end{array}$ & 0.8025 \\
\hline \multicolumn{7}{|l|}{ Biological sex } \\
\hline Male & $339.06(768.70)$ & - & - & $190.36(423.28)$ & - & - \\
\hline Female & $317.35(849.92)$ & $\begin{array}{l}-0.46 \\
{[-29.97,29.05]}\end{array}$ & 0.9757 & $187.40(392.82)$ & $\begin{array}{l}-1.33 \\
{[-10.93,8.27]}\end{array}$ & 0.7856 \\
\hline \multicolumn{7}{|c|}{ Primary language } \\
\hline English & $328.05(806.34)$ & - & - & $188.42(415.54)$ & - & - \\
\hline Non-English & 352.67 (799.07) & $\begin{array}{l}18.07 \\
{[-52.02,88.15]}\end{array}$ & 0.6134 & $192.35(224.16)$ & $\begin{array}{l}-6.04 \\
{[-27.43,15.35]}\end{array}$ & 0.5799 \\
\hline \multicolumn{7}{|l|}{ Triage level } \\
\hline 1 & $\begin{array}{l}1,418.81 \\
(2,057.78)\end{array}$ & - & - & $389.27(767.42)$ & - & - \\
\hline 2 & $290.82(682.74)$ & $\begin{array}{l}-1,096.13[1,165.16 \\
-1,027.11]\end{array}$ & $<0.0001$ & $200.27(453.60)$ & $\begin{array}{l}-181.22 \\
\text { [-220.47, } \\
-141.98] \\
\end{array}$ & $<0.0001$ \\
\hline 3 & $186.81(290.77)$ & $\begin{array}{l}-1,191.06 \\
{[-1,268.95,} \\
-1,113.16]\end{array}$ & $<0.0001$ & $150.12(200.25)$ & $\begin{array}{l}-181.22 \\
{[-220.47,} \\
-141.98]\end{array}$ & $<0.0001$ \\
\hline
\end{tabular}

${ }^{\text {aS }}$ elf reported by patients upon registering with staff members specifically trained in asking how patients identify in terms of their race.

ophthalmic concern, regardless of urgency of the diagnosis at that visit. Patient were more likely to have longer visits if designated by the triage nurse to be Triage Category 1 urgency. This aligns with the intention of the triage system, which identifies patients with more acute and complex problems. Patients were also more likely to have longer visits if they presented from out-of-state for both urgent and nonurgent diagnoses; this may be due to patients presenting with more complex problems, or seeking second opinions, when traveling from further distances. Finally, possession of several types of non-private insurance (Accidental, CHIP, Medicare and Medicaid for urgent visits and Accidental, CHP and Medicaid for urgent visits) was associated with longer visit durations. There is a need for further investigation into this. This may suggest that patients on these plans have more complex eye problems requiring more extensive care. However, this may also be due to unconscious bias on the behalf of health care providers to prioritize or treat wellinsured patients more expeditiously.

Patients presenting to the MEE ED are often offered follow-up depending on the nature of their problem. Follow-up at MEE is not offered uniformly, as patients may have diagnoses that do not require it or may have their own eye care physicians outside of our system, with whom they choose to pursue subsequent care. Follow-ups at MEE can take place in a specialized "ED follow-up" clinic, in a general eye clinic, in a specialty clinic, or in the ED as a "follow-up" if none of these appointments are available. Because ED visits can result in surgical intervention, encounters in the operating room subsequent to an anchor ED visit were also considered to be follow-up. Out-of-state residency decreased the chance of follow-up for both urgent and non-urgent visits; this is likely because of barriers to travel and patients electing to follow-up closer to home. This may suggest the importance of expansion of specialty care into the community to improve accessibility. Again, insurance type impacted the chance of follow-up visit for both urgent and non-urgent diagnoses; this requires further investigation to determine barriers to accessing care in this population. Despite initial differences in time to follow-up suggested in single variable tests and demonstrated in the KM plots, there was ultimately no difference in time to follow-up based on Hispanic versus non-Hispanic ethnicity or based on primary language when controlling for other variables. This was likely due to colinearity of these two variables, with race. There were two findings in the follow-up visit analysis which can point to significant differences in care due to social determinants of health. Compared with White patients, Black patients had a 
A Retrospective Study of Disparities Szypko et al. e283

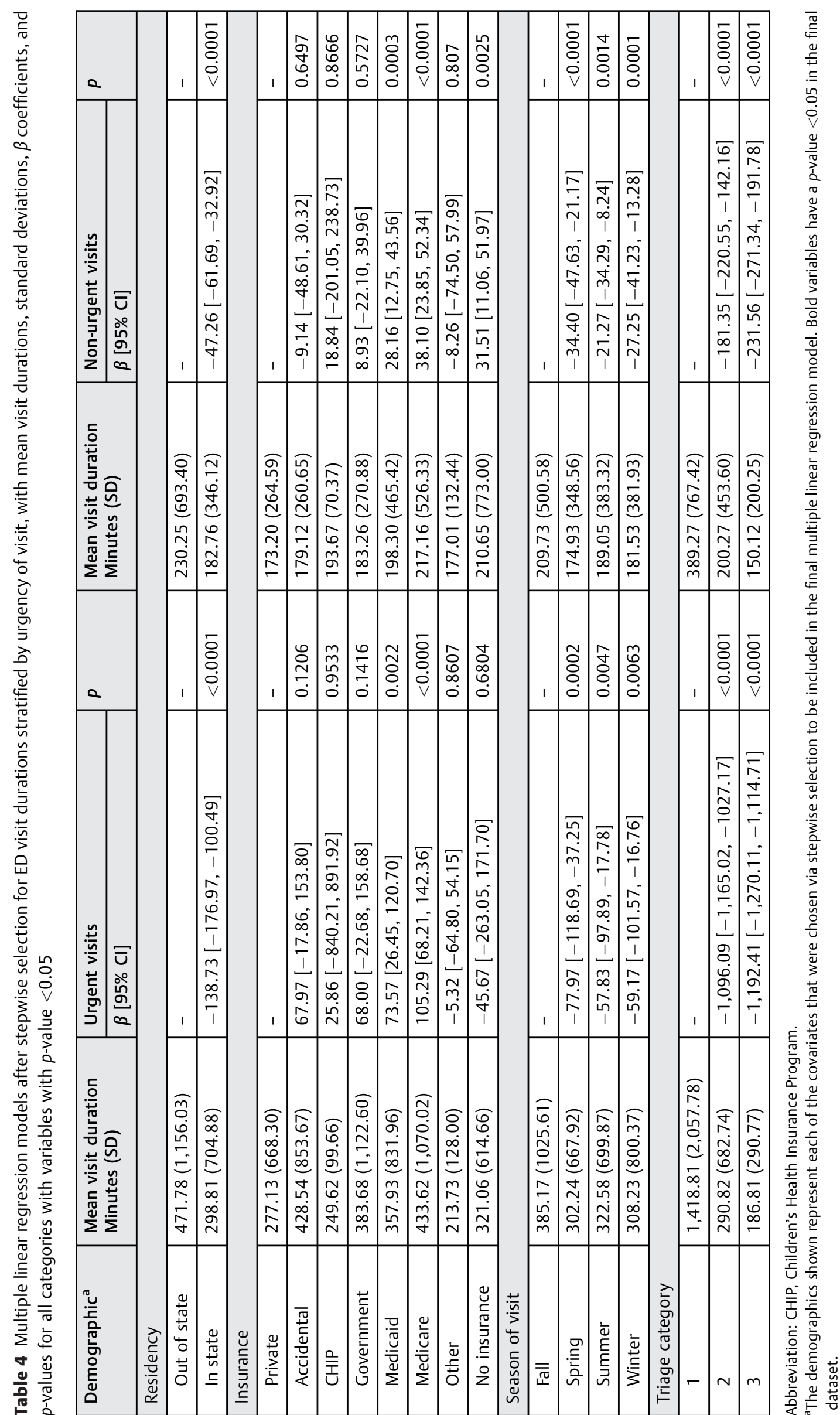


e284 A Retrospective Study of Disparities Szypko et al.

Table 5 Hazard ratios for time to next visit after initial ED visit, urgent and non-urgent, with hazard ratios and $p$-values for all variables with $p$-value $<0.05$

\begin{tabular}{|c|c|c|c|c|}
\hline \multirow[t]{2}{*}{ Demographic $^{a}$} & \multicolumn{2}{|l|}{ Urgent visits } & \multicolumn{2}{|l|}{ Non-urgent visits } \\
\hline & $\mathrm{HR}[95 \% \mathrm{Cl}]$ & $p$ & $\mathrm{HR}[95 \% \mathrm{Cl}]$ & $p$ \\
\hline \multicolumn{5}{|l|}{ Residency } \\
\hline In state & - & - & - & - \\
\hline Out of state & $0.91[0.85,0.97]$ & 0.0037 & $0.94[0.88,0.99]$ & 0.0266 \\
\hline \multicolumn{5}{|l|}{ Primary Insurance } \\
\hline Private & - & - & - & - \\
\hline Accidental & $0.79[0.67,0.93]$ & 0.0005 & $1.23[1.06,1.43]$ & 0.0062 \\
\hline $\mathrm{CHIP}$ & $1.67[0.42,6.70]$ & 0.4696 & $9.55[3.07,29.71]$ & 0.0001 \\
\hline Government & $0.89[0.76,1.03]$ & 0.1193 & $0.89[0.79,1.00]$ & 0.0503 \\
\hline Medicaid & $0.89[0.82,0.96]$ & 0.0037 & $1.00[0.95,1.07]$ & 0.8721 \\
\hline Medicare & $0.92[0.87,0.98]$ & 0.009 & $0.94[0.91,0.98]$ & 0.0068 \\
\hline Other & $1.33[0.93,1.92]$ & 0.1212 & $1.18[0.91,1.55]$ & 0.2175 \\
\hline No insurance & $1.01[0.91,1.12]$ & 0.8714 & $0.96[0.88,1.04]$ & 0.3259 \\
\hline \multicolumn{5}{|l|}{ Season of visit } \\
\hline Fall & - & - & - & - \\
\hline Spring & $1.05[0.98,1.12]$ & 0.1928 & $1.05[1.00,1.11]$ & 0.0375 \\
\hline Summer & $1.02[0.95,1.09]$ & 0.5793 & $0.98[0.93,1.03]$ & 0.3542 \\
\hline Winter & $1.01[0.95,1.09]$ & 0.7035 & $1.09[1.03,1.15]$ & 0.0011 \\
\hline \multicolumn{5}{|l|}{ Race } \\
\hline White & - & - & - & - \\
\hline American Indian & $0.82[0.41,1.65]$ & 0.5848 & $1.17[0.78,1.74]$ & 0.4512 \\
\hline Asian & $1.02[0.93,1.13]$ & 0.6417 & $0.99[0.92,1.06]$ & 0.6804 \\
\hline Black & $0.91[0.84,0.98]$ & 0.0143 & $1.02[0.96,1.07]$ & 0.5792 \\
\hline Hawaiian & $0.91[0.58,1.43]$ & 0.6841 & $0.91[0.68,1.22]$ & 0.5341 \\
\hline Hispanic & $0.87[0.68,1.12]$ & 0.2947 & $0.86[0.72,1.02]$ & 0.0846 \\
\hline \multicolumn{5}{|c|}{ Ethnicity (Hispanic vs. non-Hispanic) } \\
\hline Non-Hispanic & - & - & - & - \\
\hline Hispanic & $0.89[0.78,1.01]$ & 0.0788 & $1.06[0.97,1.17]$ & 0.2019 \\
\hline \multicolumn{5}{|l|}{ Listed PCP } \\
\hline No & - & - & - & - \\
\hline Yes & $0.98[0.93,1.03]$ & 0.417 & $0.82[0.78,0.86]$ & $<0.0001$ \\
\hline \multicolumn{5}{|l|}{ Biological sex } \\
\hline Male & - & - & - & - \\
\hline Female & $1.03[0.98,1.08]$ & 0.2581 & $0.90[0.87,0.93]$ & $<0.0001$ \\
\hline \multicolumn{5}{|l|}{ Primary Language } \\
\hline English & - & - & - & - \\
\hline Non-English & $0.95[0.85,1.06]$ & 0.3473 & $0.99[0.92,1.07]$ & 0.8315 \\
\hline
\end{tabular}

Abbreviation: CHIP, Children's Health Insurance Program.

significantly decreased chance of having a follow-up visit for urgent diagnoses. This was not found to be true for nonurgent diagnoses. Compared with male patients, female patients had a significantly decreased chance of having a follow-up visit for non-urgent diagnoses. These two findings merit further investigation into the cause of the disparities.
This could be due to patient preference, but also could be an evidence of unconscious bias in the process of offering follow-up visits to these patients. There could also be differences in the ability of different groups to return even if given an appointment. This may suggest a need for better oversight from a care coordination perspective to ensure that all 


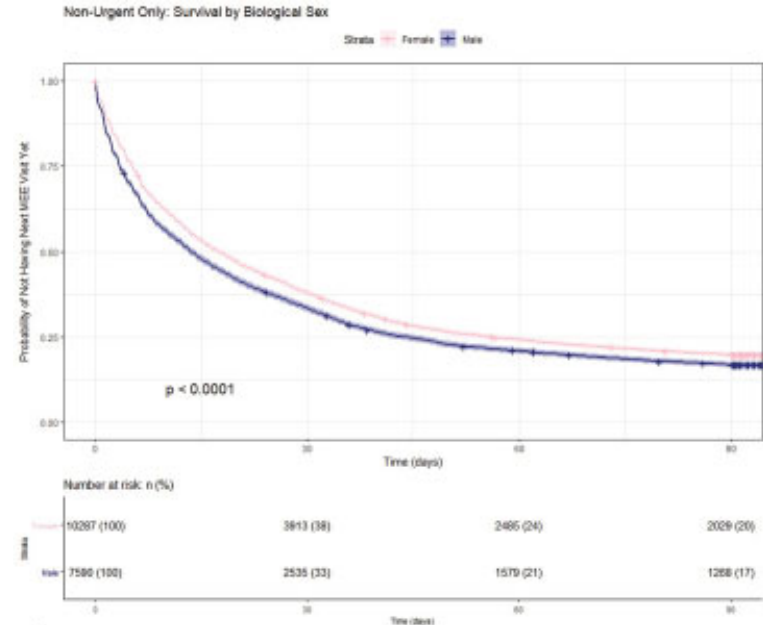

A

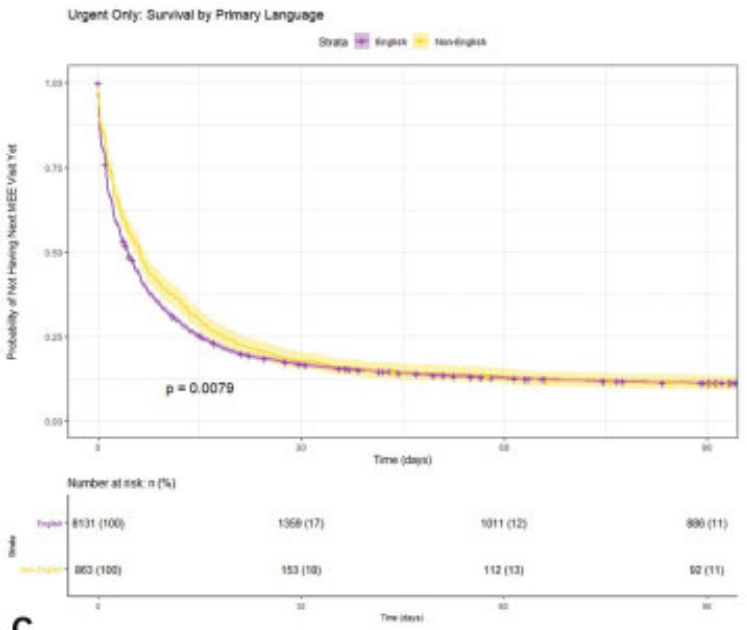

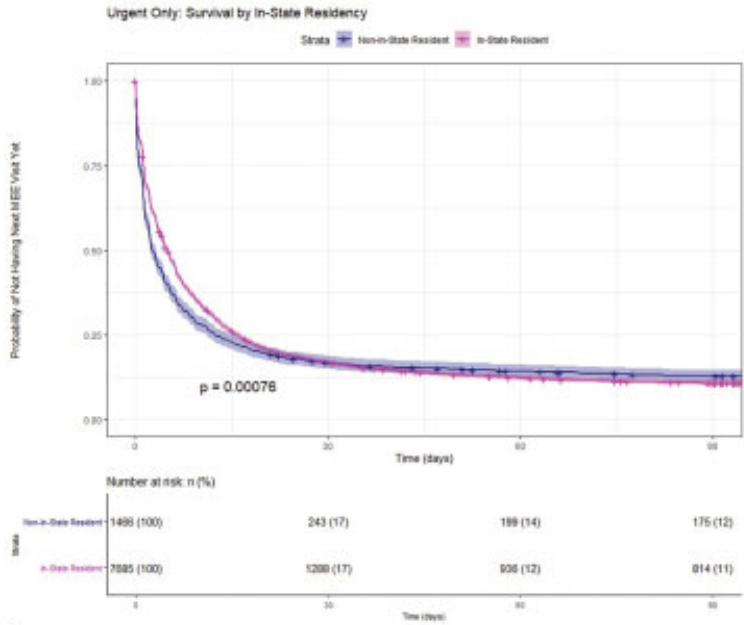

B

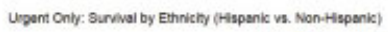

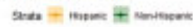

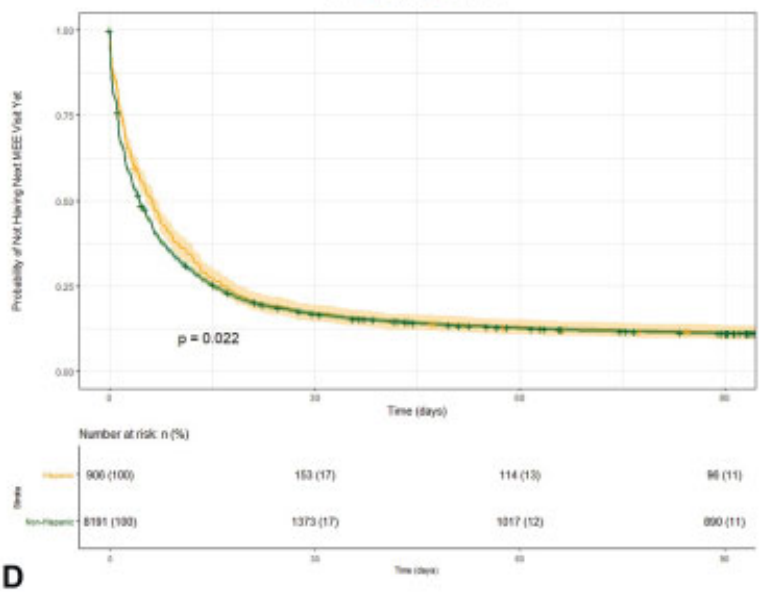

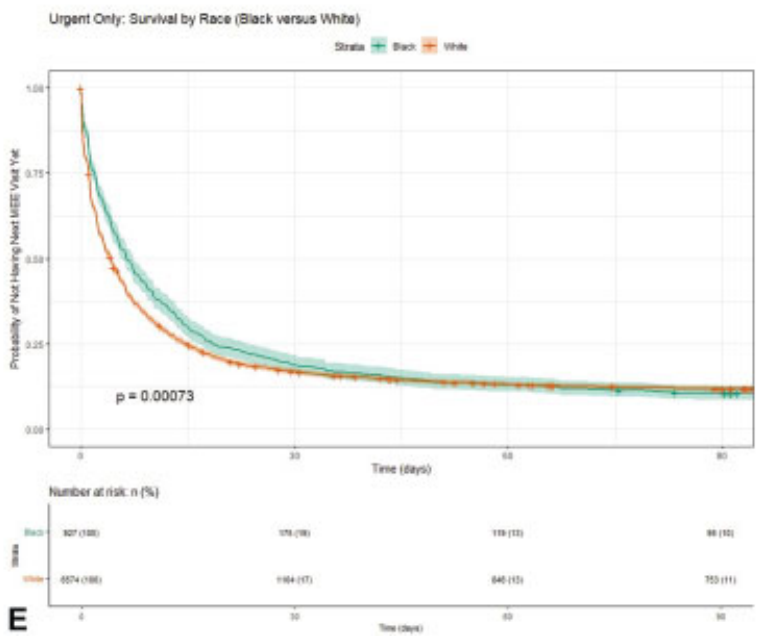

Fig. 1 Kaplan Meier plots for significant variables. (A) Survival analysis of continued care following non-urgent ED visits stratified by biological sex. (B) Survival analysis of continued care following urgent ED visits stratified by patient residency. (C) Survival analysis of continued care following urgent ED visits stratified by primary language. (D) Survival analysis of continued care following urgent ED visits stratified by ethnicity (Hispanic vs. non-Hispanic). (E) Survival analysis of continued care following urgent ED visits stratified by race (Black vs. White).

patients are offered and receive appropriate follow-up care after an ED visit.

This study was limited by the inability to accurately measure wait time rather than visit duration; we are unable to determine how much of the visit duration was spent in the waiting room compared with under care by a physician. Time stamping practices, although standardized, could also vary by staff member. In addition, we are unable to capture follow-up visits that did not occur within our system and so are only able to include patients who returned to seek care 
at MEE. We are also unable to determine whether patients were offered follow-up visits and did not pursue them, or were not offered to them. We did not investigate whether follow-up appointments were scheduled but only whether patients attended a follow-up visit; patients may have been unable to attend scheduled follow-up visits due to various factors. Further investigation would better inform the determinants of these disparities in follow-up. Finally, the designation of urgent versus non-urgent diagnoses may not correlate with the urgency of the chief complaint; one chief complaint, such as floaters, could result in a non-urgent diagnosis, like vitreous syneresis, or an urgent diagnosis, like retinal detachment. Therefore, this designation as urgent or non-urgent diagnosis may not reflect on the necessity of the visit. Finally, the EMR did contain a field that comprised options for patient ethnicities; this field contained upwards of 100 ethnicities. We elected to use only a second field designating patients as Hispanic versus non-Hispanic for the ease of analysis but further research looking at a broader set of ethnicities in a larger dataset would be worthwhile.

In conclusion, this study models one way in which the field of ophthalmology can examine the social determinants of ophthalmic care, by examining the impact of various demographic factors on ED visit durations and completion of a follow-up visit. $79.84 \%$ of patients presenting with initial ED visits in this study were White, which does not reflect the overall demographic of the surrounding city of Boston which is $52.4 \%$ White but is closer to that of the state of Massachusetts which is $80.6 \%$ White. ${ }^{25}$ This may suggest that our ED does not adequately serve the immediate surrounding population. Overall, findings were reassuring in that only patient residency and insurance states uniformly impacted these process metrics. However, race and sex did impact the likelihood of patient follow-up after an initial ED visit.

Issues of disparity in care based on demographic factors have become increasingly recognized across medicine. Disparities certainly exist as well in the field of ophthalmology and further studies identifying potential sources of this can lead to improvement both in process and potential outcomes of care.

\section{Financial Disclosures}

None.

\section{Funding}

There was no government or non-government support for this paper.

\section{Conflict of Interest}

Dr. Matthew Gardiner receives royalties for contributions to UpToDate.

\section{Acknowledgments}

None.

\section{References}

1 Hooker EA, Mallow PJ, Oglesby MM. Characteristics and trends of emergency department visits in the United States (2010-2014). J Emerg Med 2019;56(03):344-351
2 National Hospital Ambulatory Medical Care Survey: 2017 Emergency Department Summary Tables. Published online 2017:37 accessed on March 3, 2021 at: cdc.gov/nchs/data/nnames/webtables/2017_ed_web_tables-508.pdf

3 Levine DM, Linder JA, Landon BE. Characteristics of Americans with primary care and changes over time, 2002-2015. JAMA Intern Med 2020;180(03):463-466

4 Barish RA, McGauly PL, Arnold TC. Emergency room crowding: a marker of hospital health. Trans Am Clin Climatol Assoc 2012; 123:304-310, discussion 310-311

5 Enard KR, Ganelin DM. Exploring the value proposition of primary care for safety-net patients who utilize emergency departments to address unmet needs. J Prim Care Community Health 2017;8 (04):285-293

6 Durand AC, Gentile S, Devictor B, et al. ED patients: how nonurgent are they? Systematic review of the emergency medicine literature. Am J Emerg Med 2011;29(03):333-345

7 Doran KM, Raven MC, Rosenheck RA. What drives frequent emergency department use in an integrated health system? National data from the Veterans Health Administration. Ann Emerg Med 2013;62(02):151-159

8 LaCalle E, Rabin E. Frequent users of emergency departments: the myths, the data, and the policy implications. Ann Emerg Med 2010;56(01):42-48

9 Pulse Reports for the Emergency Department. 2011 Press Ganey Pulse Report. Press Ganey. Updated 2011. Accessed March 2021 at: https://helpandtraining.pressganey.com/Documents_secure/ Pulse\%20Reports/2011_Press_Ganey_Pulse_Report.pdf

10 Wilper AP, Woolhandler S, Lasser KE, et al. Waits to see an emergency department physician: U.S. trends and predictors, 1997-2004. Health Aff (Millwood) 2008;27(02):w84-w95

11 Horwitz LI, Green J, Bradley EH. US emergency department performance on wait time and length of visit. Ann Emerg Med 2010;55(02):133-141

12 Dehon E, Weiss N, Jones J, Faulconer W, Hinton E, Sterling S. A systematic review of the impact of physician implicit racial bias on clinical decision making. Acad Emerg Med 2017;24(08):895-904

13 Qiao WP, Powell ES, Witte MP, Zelder MR. Relationship between racial disparities in ED wait times and illness severity. Am J Emerg Med 2016;34(01):10-15

14 Chang DC, Britt LD, Cornwell EE. Racial disparities in emergency surgical care. Med Clin North Am 2005;89(05):945-948, 947

15 James CA, Bourgeois FT, Shannon MW. Association of race/ethnicity with emergency department wait times. Pediatrics 2005;115(03):e310-e315

16 Bazarian JJ, Pope C, McClung J, Cheng YT, Flesher W. Ethnic and racial disparities in emergency department care for mild traumatic brain injury. Acad Emerg Med 2003;10(11):1209-1217

17 DeVon HA, Burke LA, Nelson H, Zerwic JJ, Riley B. Disparities in patients presenting to the emergency department with potential acute coronary syndrome: it matters if you are Black or White. Heart Lung 2014;43(04):270-277

18 López L, Wilper AP, Cervantes MC, Betancourt JR, Green AR. Racial and sex differences in emergency department triage assessment and test ordering for chest pain, 1997-2006. Acad Emerg Med 2010;17(08):801-808

19 Park CY, Lee MA, Epstein AJ. Variation in emergency department wait times for children by race/ethnicity and payment source. Health Serv Res 2009;44(06):2022-2039

20 Pines JM, Russell Localio A, Hollander JE. Racial disparities in emergency department length of stay for admitted patients in the United States. Acad Emerg Med 2009;16(05):403-410

21 Massachusetts Eye and Ear Quality and Outcomes. Department of Ophthalmology, 2020. Accessed on March 14, 2021 at: https:// www.masseyeandear.org/assets/MEE/pdfs/about/2020-QualityOutcomes-Ophthalmology-Report.pdf

22 Akaike H. Information theory and an extension of the maximum likelihood principle. In: Petrov BN, Csaki BF, eds. Paper presented 
at: Second International Symposium on Information Theory. Academiai Kiado; 1973:267-281

23 Lagakos SW, Schoenfeld DA. Properties of proportional-hazards score tests under misspecified regression models. Biometrics 1984;40(04):1037-1048
24 Lin DY, Wei LJ. The robust inference for the cox proportional hazards model. J Am Stat Assoc 1989;84(408):1074-1078

25 QuickFacts. Massachusetts. United States Census Bureau website. Updated July 1, 2019. Accessed March 2021 at: https://www. census.gov/quickfacts/MA 